\title{
THE TRANSEPTAL APPROACH TO THE LEFT ATRIUM IN MITRAL REGURGITATION
}

\author{
BY \\ P. G. F. NIXON \\ From the General Infirmary, Leeds
}

(RECEIVED FOR PUBLICATION FEBRUARY 9, 1960)

In the near future it should be possible to estimate the severity of mitral regurgitation and select patients for operation on purely clinical grounds. In the present state of knowledge haemodynamic data are obtained from right and left heart catheterization to give accuracy to the diagnosis of the individual case and quantitative meaning to the physical signs of the disease.

Catheterization must not cause discomfort or pain. The patient must be able to lie quietly at rest under basal conditions so that measurement of cardiac output by the Fick principle is accurate. The position of the patient and the working conditions of the room should permit recording of heart sounds. It should be possible to obtain pressures and take blood samples from each side of the heart and to inject dye into the left atrium.

Needle puncture of the left atrium through the fossa ovalis in the course of orthodox right heart catheterization is a new development which allows these conditions to be fulfilled. It was first performed by Ross (1959), and Ross, Braunwald, and Morrow (1959) have reported their experience in 13 patients. The kindness of these workers permitted me to learn the technique in the Clinic of Surgery at the National Heart Institute, Bethesda, Md., U.S.A.

The purpose of this communication is to report the experience of transeptal puncture in a further 32 patients and to describe a method of investigation well adapted to the problems of mitral regurgitation.

\section{Technique of Right and Left Heart CATHETERIZATION}

The day before investigation the patient is introduced to the laboratory staff and made familiar with the room and its equipment. He practises breathing through the mouthpiece of a Douglas bag. The procedure which will be followed the next day is explained. A penetrating chest radiograph is taken to show left atrial size and position.

For catheterization the patient is fasting, and premedicated with omnopon and pentobarbitone. He lies supine on a padded $x$-ray table.
The earpiece of the Cambridge apparatus for recording indicator dilution curves is attached to the pinna, microphones are affixed by suction to the praecordium, and E.C.G. electrodes are fastened to the limbs.

Under local anaesthesia an indwelling needle is inserted into the brachial or radial artery; and the long saphenous vein is exposed. Through it a cardiac catheter is passed onwards under fluoroscopic control to the pulmonary artery.

When the pulmonary artery "wedge" pressure has been recorded the catheter tip is withdrawn to the main pulmonary artery and the cardiac output is measured by the Fick principle by which expired air is collected for three minutes during which blood samples are withdrawn simultaneously from the main pulmonary and brachial arteries. The brachial artery pressure is recorded.

Immediately afterwards the patient breathes oxygen for five minutes, Coommassie blue dye is injected into the main pulmonary artery, and a quantitative indicator dilution curve is recorded.

The cardiac catheter is then removed, and pressures are recorded as its tip passes from pulmonary artery to right atrium.

The tip of a short No. 9 cardiac catheter (Fig. 1a) with detachable hub is now introduced into the right atrium from the long saphenous vein. The hub is removed so that the Ross needle (Fig. 1b) can be passed through the lumen until its point is just concealed by the tip of the catheter. Under fluoroscopic control the tip of the catheter is guided by the annulus ovalis into the fossa ovalis.

When the tip of the catheter is bedded down in the floor of the fossa ovalis the point of the needle is advanced $15 \mathrm{~mm}$. in a posterior and medial direction to penetrate the thin septum and lie in the left atrium.

A fine polyethylene catheter (Clay-Adams, size P.E.50) is then passed through the Ross needle until it lies in the left atrium. It may be manœuvred into the left ventricle, when simultaneous pressures can be recorded from that chamber and the brachial artery. Pressure is recorded continuously as the tip of the polyethylene catheter is withdrawn from the left ventricle to the atrium.

Dye is injected into the left atrium and a quantitative indicator-dilution curve is obtained.

After this has been done the heart sounds are recorded simultaneously with the left atrial pressure pulse. 


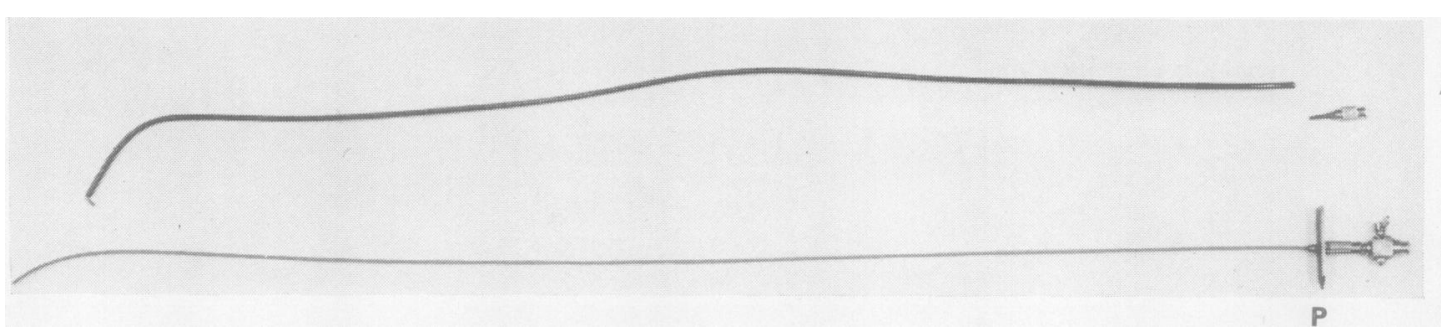

FIG. 1.-A, The short (15 mm. shorter than the Ross needle) No. 9 cardiac catheter. The hub can be removed to permit insertion of the Ross $\vec{O}$ needle. B, The Ross needle. Length $61 \mathrm{~cm} ., 17$ gauge thin wall. At the base is a Luer lock female connexion and a tap. The pointer (P) indicates the direction in which the tip is pointing. (Manufactured by the Becton-Dickinson Co., Rutherford, N.J., and $\times$ obtainable through Messrs. Thackrays of Leeds.)

Finally the respiratory quotient and brachial arterial pressure are measured as a check against alteration in the patient's state from the time of estimating cardiac output by the Fick technique.

\section{RESULTS}

The method of catheterization described has been used in six patients with mitral stenosis, in 21 with mitral incompetence, in one with constrictive pericarditis, in one with myxoma of the left atrium, in one with idiopathic pulmonary hypertension, and in two with aortic stenosis.

In every case the left atrium has been entered satisfactorily. Some difficulty in finding the fossa ovalis with the tip of the catheter was experienced in two patients who had aneurysmal dilatation of the atria.

Transient pericardial pain and friction occurred after catheterization in one patient early in the series. It is probable that this was caused by puncture of the posterior wall of an unusually small left atrium when the needle tip was aimed almost directly backwards, and not in a posterior and medial position. This complication is the only one so far encountered and it should not recur.

The polyethylene catheter passed into the left ventricle in five cases out of the 10 in which a serious attempt was made to enter that chamber. No attempt was made to enter the aorta.

The point of the Ross needle has remained in the left atrium for periods of half an hour without detectable ill effect.

\section{Discussion}

Before Ross developed the technique of transeptal puncture it had already been possible to insert a needle into the left atrium by three different routes.

The transbronchial method (Facquet, Lemoine, Alhomme, and Lefebvre (1952); Allison and Linden (1953); Morrow, Braunwald, Haller, and Sharp (1957) ) requires the services of a skilled endoscopist. Unless a fine plastic catheter is left in the heart when the bronchoscope is withdrawn it is not easy to have the patient in a basal condition $N$ and measure oxygen consumption while pressures $\mathrm{G}$ are being recorded. In my experience the heart rate during bronchoscopy is generally too rapid for $\vec{c}$ diastasis to be demonstrated in cases with mitral $\mathbb{D}$ regurgitation.

The posterior percutaneous puncture technique introduced by Björk, Malmström, and Uggla (1953) and modified by Fisher (1955) appears to be more hazardous than the transbronchial method (Mor- $\mathscr{\odot}$ row et al., 1957). The patient has to lie face downwards in a position which makes the recording $\&$ heart sounds difficult.

Radner's (1955) method of passing a needde through the aorta and the pulmonary artery intô the left atrium from the suprasternal notch does not $\stackrel{\nabla}{\square}$ permit catheterization of the left ventricle (Annotation, Lancet, 1957).

Half the attempts to pass a polyethylene catheter into the left ventricle were successful in the present series. For a number of reasons it is probable that a higher success rate will be obtained in future. First, in early attempts the Ross needle was not directed medially enough while the polyethylene catheter was threaded through it. Secondly, most of the patients suffered from severe mitral regurgitation. Thirdly, a soft polyethylene catheter was used instead of stiffer extruded nylon tubing. Attention has already been drawn to the importance of using nylon catheters when the mitral valve is grossly incompetent (Morrow et al., 1957), but none with suitable characteristics was available when the investigations were carried out.

In severe mitral regurgitation it is possible to measure left ventricular diastolic pressure during diastasis from the left atrial pressure pulse, and so failure to catheterize the left ventricle was of little concern in the present investigation.

The method of right and left heart catheterization described makes possible the study of central and total blood volume; the measurement of cardiac output by the Fick and the dye method; the analysis 


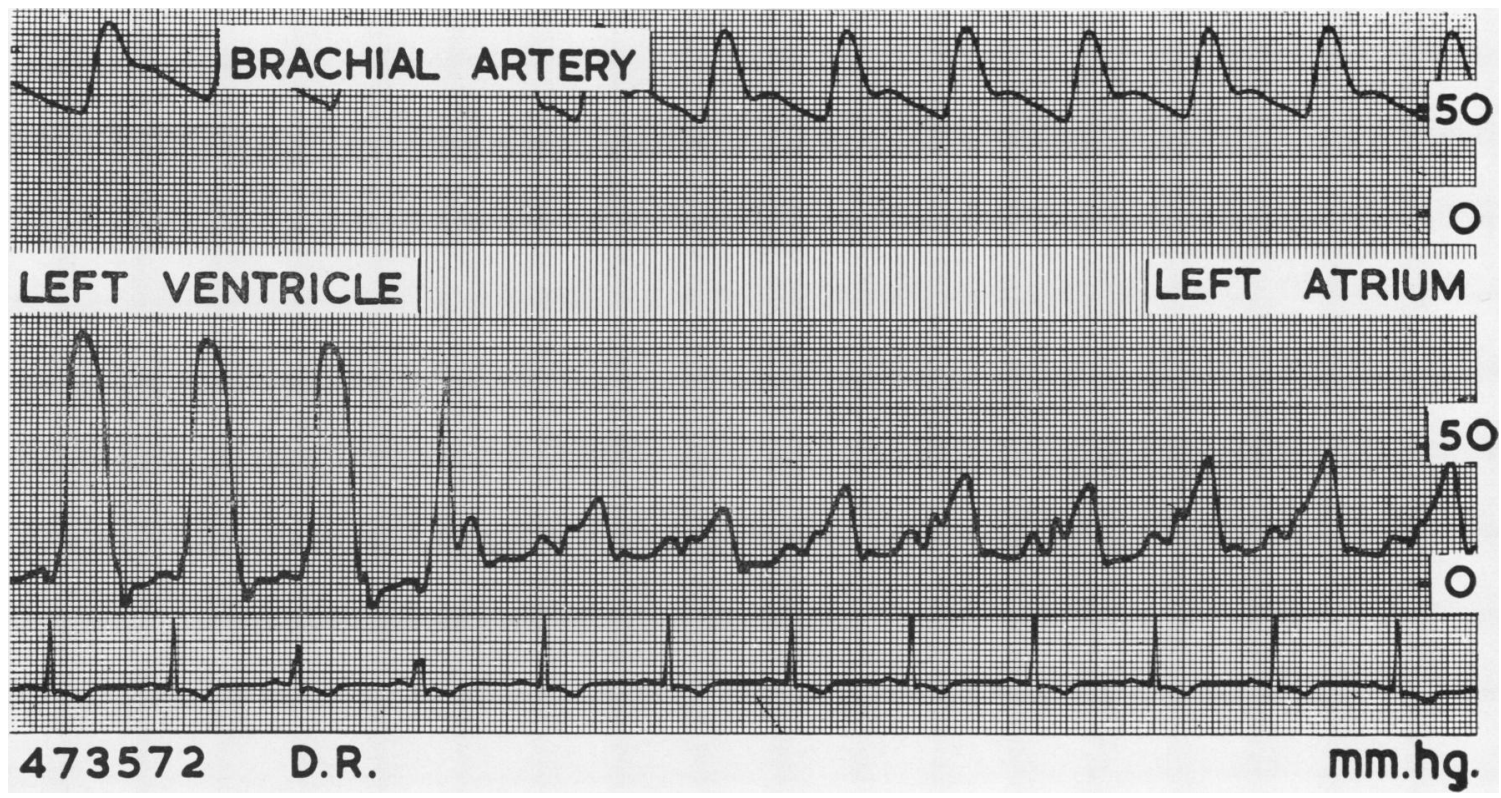

Fig. 2.-Pressure recorded as the polyethylene catheter tip was withdrawn from the left ventricle to the left atrium, with simultaneous brachial arterial pressure pulse, from a case of myxoma of the left atrium.

of indicator-dilution curves in relation to the volume between pulmonary artery and left atrium; and the examination of heart sounds in relation to left atrial and peripheral arterial pressure pulses.

To obtain undistorted pressure pulses from the atrium it is necessary either to damp the Ross needle-transducer-amplifier-recorder system, or to attach the fine plastic catheter directly to a transducer with a rigid membrane and small volume displacement. An example of a withdrawal pressure tracing from the left ventricle to the left atrium with a simultaneous brachial arterial pulse from a case of left atrial myxoma is shown in Fig. 2.

Using the Cambridge indicator-dilution apparatus it is possible to record curves with an earpiece which are satisfactory for quantitative purposes (Fig. 3) in most patients. In two patients with extreme peripheral cyanosis there was excessive damping of the indicator dilution curve attributable to a poor blood flow through the ear. A comparison of dye curves recorded with earpiece and cuvette will be published at a later date.

\section{SUMMARY}

Clinical experience with the transeptal approach to the left atrium is reported, and a technique of left and right heart catheterization adapted to the investigation of patients with mitral regurgitation is described.

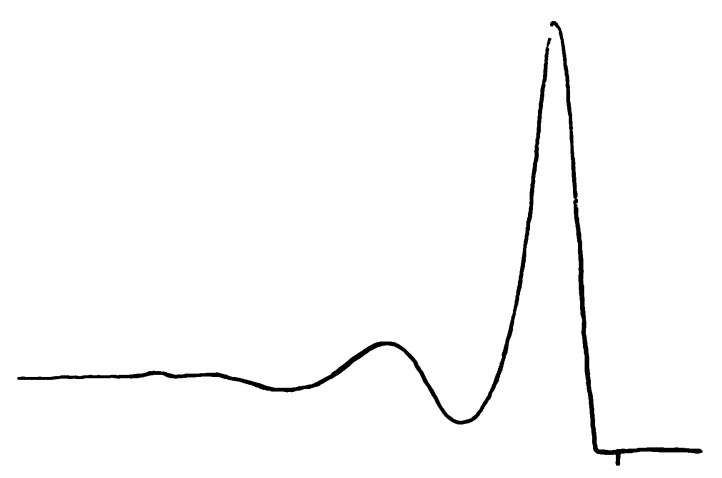

a

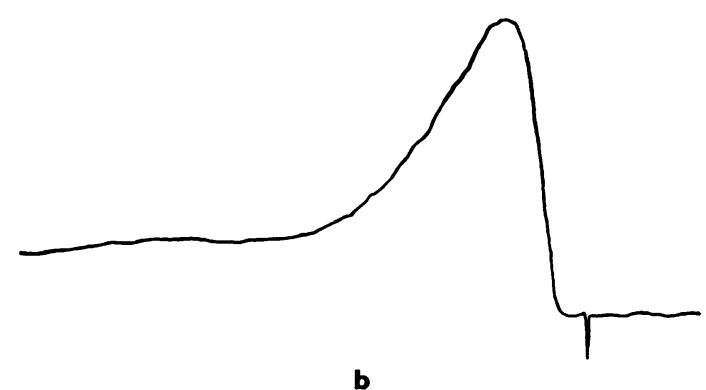

FIG. 3.-Indicator dilution curves from the Cambridge earpiece and recorder following upon injection of Coommassie blue dye into the left atrium in one patient with mitral stenosis and in one with mitral incompetence. 
I am indebted to Mr. G. H. Wooler for the opportunity to carry out this study, and deeply grateful to the Director of the National Heart Institute for the opportunity to work as guest scientist in the Clinic of Surgery with Drs. John Ross, A. G. Morrow, and E. Braunwald. I wish to thank Dr. J. H. R. Towers, Dr. W. Whitaker, and Mr. J. A. Aylwin for referring patients for investigation. Staff Nurse E. Kirkbride, Mr. M. Snow and Mr. R. Addyman are to be thanked for zealous technical assistance.

This work has been financed by generous grants from the Nuffield Foundation, the Endowment Fund of the Infirmary, and the Medical Research Council.

\section{REFERENCES}

Allison, P. R., and Linden, R. J. (1953). Circulation, 7, 669. Björk, V. O., Malmström, G., and Uggla, L. G. (1953). Ann. Surg., $138,718$.
Facquet, J., Lemoine, J. M., Alhomme, P., and Lefebvre, J. (1952). Arch. Mal. Coeur, 45, 741.

Fisher, D. L. (1955). J. thorac. Surg., 30, 379.

Lancet (1957), 2, 630 (Annotation).

Morrow, A. G., Braunwald, E., Haller, A., and Sharp, E. H. (1957). Circulation, 16, 1033.

Radner, S. (1955). Acta med. scand., 151, 223.

Ross, J. Jr. (1959). Ann. Surg., 149, 395.

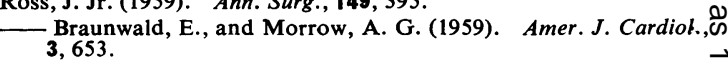

\section{AdDendum}

Septal puncture has been performed without complication on 52 occasions since this paper was $\vec{c}$ submitted for publication. In two patients with aneurysmal dilatation of the heart it was notiv possible to reach the fossa ovalis with the needle tip. ज 